\title{
O papel do estágio docência no desenvolvimento de competências didático-pedagógicas no contexto da pós-graduação em Contabilidade
}

\author{
Layne Vitória Ferreira \\ https://orcid.org/0000-0002-2397-8410 | E-mail:lyvferreira@gmail.com \\ Edvalda Araújo Leal \\ https://orcid.org/0000-0002-7497-5949 | E-mail:edvalda@ufu.br \\ Raíssa Silveira de Farias \\ https://orcid.org/0000-0001-9722-442X | E-mail: farias.issa@gmail.com
}

\section{Resumo}

Objetivo: Identificar as competências desenvolvidas no estágio docência para a formação didáticopedagógica por meio da percepção dos pós-graduandos da área contábil e professores orientadores/ supervisores do estágio.

Método: A pesquisa foi realizada em duas etapas: na primeira, foram realizados dois grupos focais com a participação de discentes de um Programa de Pós-graduação em Contabilidade (PPGCC) e a segunda consistiu em entrevistas semiestruturadas com cinco docentes do mesmo programa, supervisores de estágio. A análise dos dados resultou em três categorias: a função do estágio docência; as habilidades e competências proporcionadas pelo estágio na formação docente; e a visão dos sujeitos do estudo a respeito dos desafios enfrentados durante o estágio.

Resultados: Verificou-se que o estágio docência pode contribuir para a formação do discente ao associar o conhecimento teórico à prática do ensino, estimulando o desenvolvimento de competências requeridas na docência. Identificaram-se fragilidades na estrutura pedagógica proposta para o oferecimento do estágio docência na pós-graduação.

Contribuições: A pesquisa contribui para a reflexão sobre o aprimoramento do processo de estágio docência, ao propor que seus objetivos educacionais estejam mais claros e que um mecanismo de sistematização desse processo seja desenvolvido pelos Programas de Pós-graduação, a fim de assegurar ao discente um acompanhamento adequado por parte do professor que o orienta/supervisiona.

Palavras-chave: Estágio docência, Aprendizagem experiencial, Competências didático-pedagógicas, Ensino contábil. 


\section{Introdução}

A formação pedagógica do professor que atua no ensino superior tornou-se alvo de várias pesquisas na área educacional (Ferreira \& Hillen, 2015; Nganga; Botinha; Miranda \& Leal, 2016; Patrus \& Lima; 2014). A principal exigência requerida para o exercício da docência nesse nível de ensino era o curso de bacharelado e a experiência profissional (Masetto, 2012). Acreditava-se que o conhecimento em determinada área era suficiente para ensinar, o que contribuía para que o recrutamento dos professores se pautasse na sua competência profissional (Gil, 2008). Dessa forma, os docentes aprendiam a ensinar por meio da prática e, embora isso contribuísse de alguma forma para que eles se tornassem professores, eles não tinham a qualificação pedagógica sistematizada (Pimenta, 2009).

$\mathrm{O}$ ato de ensinar é, portanto, um processo complexo, pois não se restringe ao conhecimento acerca de um determinado conteúdo, mas abrange ainda aspectos como a aprendizagem dos alunos, a forma como essa aprendizagem será conduzida e a escolha das estratégias de ensino que viabilizarão o processo de ensino-aprendizagem (Zabalza, 2003).

Para tanto, torna-se necessária a formação para o exercício da docência, a qual deve ocorrer, prioritariamente, em Programas de Pós-graduação stricto sensu, conforme determina a Lei de Diretrizes e Bases da Educação Nacional (LDB), de 1996. Essa diretriz é também estabelecida pela Coordenação de Aperfeiçoamento de Pessoal de Nível Superior (Capes), que justifica a necessidade do oferecimento de mestrados e doutorados eficientes e de qualidade para a "formação de professorado competente que possa atender à demanda no ensino básico e superior, garantindo, ao mesmo tempo, a constante melhoria da qualidade" (Capes, 2014).

No entanto, a própria Capes tem fomentado uma política mais direcionada para formação de pesquisadores e com menor incentivo à formação docente para o ensino superior (Ferreira \& Hillen, 2015). Somado a isso, a ausência de indicadores de avaliação que envolvam a formação de docentes nos Programas de Pós-graduação (PPGs) no Brasil, torna esse cenário ainda mais distante do idealizado, especialmente, nos Programas de Pós-graduação em Contabilidade (PPGCCs), uma vez que são empreendidas poucas ações formais com o propósito de qualificar mestrandos e doutorandos para a prática docente (Nganga et al., 2016).

Diversos estudos destacam o foco dado à formação do pesquisador por parte dos Programas de Pósgraduação em detrimento à formação voltada para a docência, ressaltando a necessidade de ser suprida essa lacuna na formação didático-pedagógica do professor que atua no ensino de Contabilidade (Andere \& Araujo, 2008; Laffin \& Gomes, 2014; Lapini, 2012; Miranda, 2010; Miranda, Nganga et al., 2016).

Um componente didático-pedagógico que tem sido utilizado pelos Programas de Pós-Graduação, com vistas à qualificação docente é o estágio docência ou estágio supervisionado. $\mathrm{O}$ estágio docência tem como intuito preparar o aluno de pós-graduação para o exercício da docência, tornando-o apto para atuar na educação em nível de ensino superior (Capes, 2014). No entanto, Nganga et al. (2016) constataram grande heterogeneidade na forma como o estágio docência tem sido desenvolvido nos Programas de Pósgraduação stricto sensu em Ciências Contábeis.

Com base nesse contexto, o presente estudo busca identificar as competências desenvolvidas no estágio docência para a formação didático-pedagógica por meio da percepção dos pós-graduandos stricto sensu da área contábil e professores orientadores/supervisores do estágio.

Dentre as bases de dados pesquisadas (Science Direct, Redalyc, Portal de Periódicos da Capes, Portal Scielo e Google Acadêmico), constatou-se que poucos estudos na área contábil se dedicaram a verificar os componentes pedagógicos ofertados pelos PPGCCs (Comunelo, Espejo, Voese \& Lima, 2012; Miranda, 2010; Nganga et al., 2016). Nessas mesmas bases, não foram encontradas pesquisas que investigassem o papel do estágio docência na formação docente, no âmbito desses programas. 
Entende-se que investigar a percepção dos discentes e professores do PPGCC quanto às competências docentes desenvolvidas durante o estágio docência é relevante, em virtude da expansão do ensino superior ter promovido um crescimento na demanda por profissionais aptos para atuar nesse nível de ensino. Todavia, torna-se preocupante a forma como essa demanda tem sido atendida, tendo em vista que não há uma avaliação razoável acerca da formação desses profissionais (Santana \& Araújo, 2011). Diante disso, este estudo pretende evidenciar a contribuição do estágio docência no desenvolvimento de competências exigidas na docência. Ademais, espera-se ainda contribuir para que as instâncias reguladoras, bem como as instituições de ensino revejam e desenvolvam ações sistemáticas que assegurem a promoção e a valorização da formação docente nos PPGs do Brasil.

A base teórica escolhida para fundamentar a presente pesquisa é a teoria da Aprendizagem Experiencial desenvolvida por David Kolb (1984), aliada às competências necessárias à docência propostas por Zabalza (2003). Cabe ressaltar que o estudo não teve como propósito a aplicação prática da teoria da Aprendizagem Experiencial e, sim, utilizar-se de seus pressupostos, uma vez que o estágio docência é uma experiência que pode enriquecer o processo de aprendizagem do aluno.

\section{Base Teórica}

Esta seção é composta pelas discussões sobre formação docente, estágio docência e as competências didático-pedagógicas, bem como pela teoria da Aprendizagem Experiencial.

\subsection{Formação de professores, estágio docência e as competências didático-pedagógicas}

A formação didático-pedagógica é pré-requisito para a docência (Masetto, 2012). No entanto, apesar de estar prevista na LDB a responsabilidade dos PPGs pela formação docente, estudos na área contábil revelam que, nesses programas, prevalece a formação de pesquisadores (Andere \& Araujo, 2008; Miranda, 2010; Nganga et al. 2016). Isso reforça a necessidade de ampliação de espaços para formação do docente de ensino superior, em especial, a formação pedagógica de bacharéis que exercem a atividade docente e não recebem esse tipo de qualificação em nível de graduação e pós-graduação (Hillen, Laffin \& Ensslin, 2018; Nganga et al., 2016)

Diante desse contexto, o estágio docência é considerado um componente curricular aliado à preparação para a docência, sendo requerido como obrigatório para os alunos bolsistas Capes Demanda Social e opcional, para os demais, de acordo com a Portaria MEC/CAPES n. ${ }^{\circ}$ 76/2010. Importante destacar que o estágio é desenvolvido por discentes de pós-graduação stricto sensu, cujo desempenho é acompanhado pelo professor que os orienta/supervisiona durante a realização do referido componente curricular (Wall, Prado \& Carraro, 2008).

Ao considerar o estágio como componente curricular capaz de contribuir para a formação docente, este estudo tem como objetivo identificar as competências desenvolvidas pelos discentes de um curso de pós-graduação em Ciências Contábeis nesse espaço formativo.

Os enfoques relacionados à formação de professores devem visar à qualificação, capacitando-os para identificar seus objetivos profissionais, para a escolha de metodologias adequadas, para o conhecimento do conteúdo a ser ensinado, bem como para que compreendam as orientações culturais e cognitivas dos estudantes (Liston \& Zeichner, 1990). Assim, a qualificação didático-pedagógica é caracterizada por saberes docentes, que servem de base de conhecimento para o ensino reflexivo (Hillen et al., 2018).

Dentre as diversas tipologias relacionadas aos saberes docentes, este estudo se valerá das dez competências propostas por Zabalza (2003, p. 70), as quais são consideradas como um "conjunto de conhecimentos e habilidades que os sujeitos necessitam para desenvolver algum tipo de atividade", conforme apresentado na Tabela 1. 
Tabela 1

\section{Competências necessárias à docência}

1) Planejar o processo de ensino-aprendizagem

2) Selecionar e preparar os conteúdos disciplinares

3) Oferecer informações e explicações compreensíveis e bem organizadas

4) Manejo das novas tecnologias

5) Elaborar a metodologia e organizar as atividades

6) Comunicar-se e relacionar-se com os alunos

7) Tutoria
Deve considerar as determinações legais, os conteúdos básicos previstos na ementa da disciplina, a estrutura curricular na qual a mesma está inserida, a visão própria do docente em relação à disciplina e a sua didática, as características dos alunos, além dos recursos disponíveis.

Escolher os conteúdos mais importantes da disciplina de modo que atendam às necessidades formativas dos alunos, adequando-os às condições de tempo e de recursos disponíveis para que sejam acessíveis aos estudantes.

Capacidade de gerir didaticamente a informação e/ou as habilidades que pretende transmitir aos estudantes de modo a torná-las compreensíveis.

As novas tecnologias são ferramentas insubstituíveis que apresentam grande valor e efetividade no manejo de informações com fins didáticos. Esta competência envolve, o domínio de técnicas didáticas, novas competências que abrangem desde a preparação da informação até a manutenção de uma relação de tutoria por meio da rede.

Envolve as diversas tomadas de decisões dos professores ao gerir o desenvolvimento das atividades docentes e abrange a escolha de metodologias de ensino, a seleção, bem como a elaboração de tarefas instrutivas e a organização dos espaços voltados para a aprendizagem.

Essa competência envolve a capacidade de trabalhar em classes numerosas, assumir um estilo de liderança enquanto docente e manter um clima favorável em sala de aula.

Esta competência envolve os diversos tipos de tutoria, bem como as responsabilidades do tutor universitário, os dilemas da tutoria universitária, as condições de exercer a tutoria e a tutoria como empenho pessoal dos docentes.

Esta competência possibilita o professor saber avaliar para que possa agir como facilitador no processo de ensino-aprendizagem. Em virtude disso, o docente deve estar

8) Avaliar ciente quanto à natureza e ao propósito da avaliação na instituição de ensino, bem como deve conhecer os aspectos que compõem a avaliação e o seu processo de planejamento, execução, avaliação e feedback.

Esta competência propõe que a própria docência seja o objeto de análise. Por isso, ela

9) Refletir e investigar sobre o ensino sugere: a reflexão acerca da docência de modo que seja feita uma análise documentada acerca do processo de ensino-aprendizagem desenvolvido; a investigação sobre a docência, o que requer que os diversos fatores que afetam a didática universitária sejam submetidos a análises controladas; e por fim, a publicação sobre a docência.

10) Identificar-se com a instituição e trabalhar em equipe

Esta competência envolve a capacidade de saber e querer trabalhar em conjunto em um contexto institucional determinado.

Fonte: elaborado pelas autoras com base em Zabalza (2003) e Puentes, Aquino e Quillici Neto (2009).

Estudos sobre a educação contábil evidenciam as competências consideradas essenciais ao bom professor, sendo o domínio do conteúdo e a didática as que mais se destacam (Nogueira, Fadel \& Takamatsu, 2012; Rezende \& Leal, 2013; Tolentino, Silva, Costa \& Neto, 2014), bem como as competências mais esperadas pelos alunos (Antonelli, Colauto \& Cunha, 2012).

As formas utilizadas pelos Programas de Pós-graduação em Contabilidade para a formação dos futuros docentes da área foi alvo de investigação de Lapini (2012). Ao analisar 25 cursos, a autora apontou três métodos utilizados pelos cursos para a formação de professores; são eles: disciplina com preparação pedagógica, prática docente supervisionada e atividades complementares. A partir das análises realizadas, Lapini (2012) concluiu que o processo de educação continuada para o professor de Contabilidade não existe, revelando que os cursos de pós-graduação em Contabilidade, no Brasil, não preparam o aluno para a docência. 
Nganga et al. (2016), por sua vez, identificaram os componentes curriculares de formação pedagógica sistematizada presentes nos 18 programas de pós-graduação stricto sensu em Ciências Contábeis no Brasil. Os resultados encontrados evidenciaram que há uma baixa oferta de disciplinas voltadas para a formação de professores nesses programas, sendo apenas 14 ligadas à formação docente. Ao serem ofertadas, essas disciplinas são, em geral, de caráter optativo e apresentam carga horária igual ou inferior a 60 horas.

O presente estudo busca contribuir ao investigar a formação do docente de ensino superior na área contábil, à medida que busca verificar as competências desenvolvidas durante o processo de aprendizagem experiencial ao longo de uma das fases que antecede o ingresso na carreira docente, que é o estágio docência.

\subsection{Teoria da Aprendizagem Experiencial e a prática do estágio docência}

O desenvolvimento profissional, sob a ótica da teoria da Aprendizagem Experiencial desenvolvida por David Kolb (1984), ocorre quando da apropriação do sujeito das experiências vividas. Esse processo se dá a partir da ação e da reflexão contínua, a fim de que as experiências vivenciadas possam ser aperfeiçoadas e incorporadas nas ações do indivíduo. Entende-se que tais experiências podem ser adquiridas no contexto do estágio docência, principalmente, aquelas relacionadas à formação pedagógica dos pós-graduandos.

Para que a experiência seja significativa é importante reconhecer que o conhecimento não deve ser simplesmente compartilhado com as pessoas, pois é preciso incentivá-las a atuar em favor do seu próprio aprendizado (Behr \& Temmen, 2012). Conforme os autores, os indivíduos são capazes de aprender melhor ao realizarem descobertas por si mesmos.

Um estudo desenvolvido por Barbosa e Dib (2016) teve como objetivo discutir o processo de formação do docente pelas universidades, a partir do olhar e da vivência do professor e do aluno durante o estágio docência. Os autores concluíram que os discentes que tiveram orientação sobre métodos pedagógicos desempenharam o estágio docência com maior autoconfiança e desenvoltura, sendo capazes de conduzir as atividades de maneira mais didática e proveitosa para os envolvidos no processo de ensinoaprendizagem. A partir disso, depreende-se a importância de aliar teoria e prática no processo de formação do futuro docente, no sentido de qualificá-lo para o exercício de suas atividades no ensino superior.

Para Kolb (1984, p. 38), a aprendizagem experiencial é "o processo por onde o conhecimento é criado por meio da transformação da experiência. Esta definição enfatiza (...) que o conhecimento é um processo de transformação, sendo continuamente criado e recriado". Portanto, a aprendizagem experiencial abrange um conjunto de mecanismos que proporcionam às pessoas experiências capazes de instigá-las a buscar o aprendizado. Para melhorar a aprendizagem no ensino superior, deve-se dar ênfase no envolvimento dos alunos, de modo que esse processo inclua feedback em torno de seus esforços de aprendizagem (Kolb \& Kolb, 2005).

No contexto da formação dos futuros professores do ensino superior, os Programas de PósGraduação passaram a adotar o Estágio de Docência, em atendimento à Portaria n. ${ }^{\circ} 76 / 2010$, como forma de proporcionar uma experiência que permita o desenvolvimento de competências necessárias às atividades de docente, aliando teoria à prática (Joaquim, Nascimento, Vilas Boas \& Silva, 2011; Joaquim \& Vilas Boas, 2011; Joaquim, Vilas Boas \& Carrieri, 2013; Santos \& Helal,2015).

Nesse sentido, entende-se que é possível associar o estágio docência à aprendizagem experiencial defendida por Kolb (1984), tendo em vista que esse componente curricular proporciona ao discente uma série de vivências que o estimularão a aprender. 
Joaquim et al. (2011) citam alguns pontos a serem levados em consideração ao se analisar o processo do estágio docência para que a realização desse componente curricular se torne uma experiência de significativa aprendizagem, tanto para a formação do aluno como para a prática reflexiva do professor. Os autores elencam o estabelecimento "de critérios claros e objetivos dos métodos avaliativos do estágio docência e mais retorno aos estagiários" (p.1148), "a reflexividade na promoção do aprendizado e na geração de conhecimento" (p.1149) e a proximidade entre professor supervisor e futuro professor como alguns dos pontos a serem considerados em torno do estágio docência.

A relação de proximidade entre o professor supervisor e o discente durante o estágio docência é fundamental para o melhor aproveitamento desse aluno em torno do referido componente curricular, pois é nesse contexto que o estagiário poderá pensar de maneira crítica e reflexiva sobre o processo de ensinoaprendizagem no qual o exercício da docência ocorre (Rocha-de-Oliveira \& Deluca, 2017). Ademais, entende-se que a aproximação entre os dois sujeitos (professor e estagiário) possibilita um processo de reflexão sobre a prática, a fim de que sejam extraídas conclusões acerca das diversas situações vivenciadas ao longo da realização desse componente curricular.

Embora o estágio docência contribua para a formação docente do pós-graduando, tendo em vista a oportunidade que a atividade oferece ao discente de vivenciar a prática do processo educacional, há quem discorde da forma como esse componente curricular pode ser conduzido. Patrus e Lima (2014) criticam o fato de haver docentes que repassam suas responsabilidades enquanto professores da graduação para os seus orientandos da pós-graduação durante a realização do estágio docência. Segundo os autores, os alunos se encarregariam das aulas, bem como do processo educacional e de sua avaliação. Dessa forma, a aprendizagem não seria acompanhada e o aprendizado se desenvolveria com a prática.

Todavia, Joaquim et al. (2011) propõem que há cinco aspectos que devem ser considerados no processo de condução do estágio docência, a fim de garantir a contribuição do referido componente curricular no processo de formação docente do pós-graduando: (1) Planejamento da disciplina; (2) Contato profissional com a atividade docente; (3) Aproximação e relacionamento com o professor titular da disciplina; (4) Dificuldades enfrentadas no estágio docente; e (5) Aprendizagem e habilidade adquirida no desenvolvimento das atividades desempenhadas.

Tendo como base o estágio docência e a aprendizagem experiencial, o presente estudo busca identificar as competências adquiridas pelos discentes durante o período de realização do estágio docência, segundo a percepção dos pós-graduandos e seus professores orientadores/supervisores de estágio.

\section{Aspectos Metodológicos}

O presente estudo busca identificar quais competências são desenvolvidas no estágio docência para a qualificação docente, a partir da percepção dos pós-graduandos stricto sensu da área contábil e dos docentes supervisores do estágio. Para tanto, foram investigados discentes e docentes de um programa de pós-graduação na área contábil por meio de uma abordagem qualitativa, cujo propósito, para o pesquisador, é a compreensão de como as pessoas interpretam suas experiências e atribuem significados a elas (Merriam, 2009).

O estudo foi realizado em uma Instituição Pública de Ensino, localizada em Minas Gerais, que oferece o Programa de Pós-graduação em Ciências Contábeis (PPGCC). O Programa pesquisado regulamenta seu processo de estágio docência a partir da Resolução n. ${ }^{\circ}$ 002/2016. Essa resolução define as competências e habilidades mínimas a serem desenvolvidas no Estágio Docência I - voltado para os alunos de mestrado e no Estágio Docência II - direcionado aos alunos de doutorado.

A construção das evidências deste estudo ocorreu em duas etapas. A primeira etapa foi desenvolvida, utilizando-se o focus group. Para a realização dessa etapa, foram convidados 20 alunos do programa investigado, que já haviam realizado o estágio docência. O contato foi realizado via e-mail, a partir de uma lista com a relação dos discentes matriculados no programa, disponibilizada pela coordenação do curso. 
Após o envio do convite, os 16 discentes que se dispuseram a participar da entrevista foram divididos em 2 grupos distintos: 8 alunos participaram do grupo que já tinha experiência com a docência, no momento em que realizaram o estágio docência e 8 alunos compuseram o grupo dos que não tinham essa experiência ao realizar o estágio docência. Eles foram informados com antecedência sobre a data, local e horário em que ocorreriam as entrevistas.

As entrevistas foram mediadas por uma professora convidada que atua na área de negócios e que tem experiência na aplicação do referido instrumento de coleta de dados. Esse procedimento isentou as pesquisadoras do envolvimento no momento do grupo focal, embora uma delas tenha participado como ouvinte (observação).

Tabela 2

\section{Caracterização dos grupos focais}

\begin{tabular}{|c|c|c|}
\hline Descrição & Sem experiência com a docência & Com experiência na docência \\
\hline Participantes & 8 pessoas & 8 pessoas \\
\hline Sexo & 4 masculino/ 4 feminino & 4 masculino/ 4 feminino \\
\hline Idade & 23 a 30 anos & 24 a 47 anos \\
\hline Tempo de experiência com a docência & Não se aplica & 2 a 10 anos \\
\hline $\begin{array}{l}\text { Realizou estágio docência (mestrado/ } \\
\text { doutorado) }\end{array}$ & 8 pessoas no mestrado & $\begin{array}{l}3 \text { no mestrado/ } 2 \text { no doutorado/ } 3 \text { em } \\
\text { ambos }\end{array}$ \\
\hline
\end{tabular}

Fonte: elaborado pelas autoras.

A segunda etapa foi conduzida por meio de entrevistas semiestruturadas realizadas com docentes do PPGCC. Elas foram organizadas com base em um guia de entrevista composto por três questões-chave: (1) Na sua opinião, qual é a função do estágio docente para a formação do professor?; (2) Na sua opinião, quais são as habilidades e competências adquiridas pelos pós-graduandos com a participação no estágio docente?; (3) Na sua opinião, quais os principais desafios enfrentados pelo professor supervisor do estágio docente no decorrer do estágio docência?

Nessa etapa, os respondentes foram selecionados a partir do critério de proximidade com os alunos participantes da primeira etapa, a fim de realizar uma análise conjunta sobre a percepção dos dois principais agentes envolvidos no estágio docência - supervisor e estagiário. Foram convidados sete docentes e desses, cinco se dispuseram a participar do estudo. As entrevistas foram agendadas por e-mail e ocorreram via Skype com duração média de 20 minutos. Sobre a caracterização dos docentes participantes das entrevistas, temos: 4 docentes do sexo feminino e 1 docente do sexo masculino, todos eles já orientaram/supervisionaram mais de dois estagiários e suas linhas de pesquisa são: Contabilidade Governamental, Gerencial, Financeira e Ensino e Pesquisa em Contabilidade.

Para a análise de resultados, utilizou-se a abordagem de template proposta por King (2004). Nessa abordagem, as evidências são analisadas seguindo uma lista de códigos definidos, a priori, pelo pesquisador. Os dados são organizados de forma hierárquica a partir do agrupamento de códigos semelhantes, cujo objetivo é interpretar e apresentar as evidências de forma mais organizada. A Tabela 3 mostra os códigos construídos a partir da leitura das transcrições das cinco entrevistas. Os códigos de primeira ordem (Higher-order codes) foram produzidos com base no objetivo do estudo e os códigos de segunda ordem (Lower-order codes) foram elaborados com base nas dez competências necessárias à docência propostas por Zabalza (2003), detalhadas na Tabela 1 e a partir da leitura das transcrições das cinco entrevistas. Os códigos foram então agrupados conforme a temática de primeira ordem, facilitando, assim, a análise final. 
Tabela 3

Template de análise

\begin{tabular}{ll}
\hline \multicolumn{1}{c}{ Higher-order codes } & \multicolumn{1}{c}{ Lower-order codes } \\
\hline \multirow{3}{*}{ 1. Função do estágio para a } & 1.1 Experiência prática por meio da ação \\
formação docente & 1.2 Experiência prática por meio da reflexão \\
& 1.3 Experiência prática por meio da observação \\
& 1.4 Experiência prática por meio do exemplo \\
\hline & 2.1 Planejar o processo de ensino-aprendizagem \\
& 2.2 Selecionar e preparar os conteúdos disciplinares \\
& 2.3 Oferecer informações e explicações compreensíveis e bem organizadas \\
& (competência comunicativa) \\
& 2.4 Manejo das novas tecnologias \\
& 2.5 Elaborar a metodologia e organizar as atividades \\
2. Habilidades e competências & 2.6 Comunicar-se e relacionar-se com os alunos \\
proporcionadas pelo estágio & 2.7 Tutoria \\
docência & 2.8 Avaliar \\
& 2.9 Refletir e investigar sobre o ensino \\
& 2.10 Identificar-se com a instituição e trabalhar em equipe \\
\hline & 3.1 Postura do estagiário \\
& 3.2 Desenvolvimento de habilidades \\
& 3.3 (Falta de) Preparação para ser supervisor \\
& 3.4 (Falta de) Conhecimento prévio do estagiário \\
3. Principais desafios enfrentados & 3.5 Condução do estágio \\
no decorrer do estágio docência & 3.6 Duração do estágio \\
\hline
\end{tabular}

Fonte: elaborado pelas autoras.

Acerca dos códigos evidenciados na Tabela 3, bem como das transcrições dos entrevistados (discentes e docentes), utilizou-se a análise de conteúdo para o tratamento dos dados, a fim de confrontar as falas dos participantes com a literatura que serviu de suporte teórico para a construção desta pesquisa. A análise de conteúdo permite a realização de um levantamento de indicadores (quantitativos ou não), que possibilitam a execução de inferências sobre determinados conhecimentos (Cavalcante, Calixto \& Pinheiro, 2014).

Dentre as limitações do estudo, destaca-se a amostra, tendo em vista que a pesquisa foi realizada em um único PPGCC, o que inviabiliza a generalização de resultados. Além disso, cabe ressaltar que o trabalho foi submetido ao Comitê de Ética em Pesquisa com Seres Humanos da instituição onde foi conduzido, sendo aprovada sua realização conforme parecer CAAE: 93336218.7.0000.5152. Por fim, na próxima seção serão analisados e discutidos alguns trechos extraídos das entrevistas e dos grupos focais realizados. Para manter o sigilo dos participantes do estudo, serão utilizadas as letras D e E para identificar a fala dos docentes e estagiários, respectivamente, seguidas de um número distinto para identificar cada sujeito.

\section{Análise e Discussão dos Resultados}

Nesta seção, serão apresentadas as evidências encontradas com base nos três códigos de primeira ordem.

\subsection{Função do estágio para a formação docente}

Ao construir as subcategorias de análise, verificou-se que a principal função do estágio é proporcionar a experiência prática da docência aos discentes por meio da ação, da reflexão, da observação e do exemplo dado pelos supervisores durante esse processo, seja ele, positivo ou negativo. Entre as quatro subcategorias deste tópico, as falas que mais se sobressaíram mostram como principais funções do estágio as oportunidades ligadas à experiência prática e à reflexão sobre a prática. 
O estágio docência, ao ser oferecido pelos Programas de Pós-graduação, permite que os discentes vivenciem as diversas atividades desenvolvidas pelo docente do ensino superior, entre elas: o planejamento do processo de ensino-aprendizagem, a aplicação de estratégias de ensino e a elaboração e aplicação de atividades avaliativas. Essa função prática do estágio emerge na fala dos supervisores, como ilustra o trecho a seguir.

[...] eu acho que é uma oportunidade que os alunos têm de experimentar na prática as atividades que um docente precisa desenvolver. Então, eles têm a possibilidade de entender o planejamento de uma aula, como que pode ser feita a distribuição do assunto, do conteúdo durante as aulas. Eles têm a oportunidade também de desenvolver algumas estratégias pra aplicar esse conteúdo, acompanhar também os processos avaliativos, as questões dos trabalhos, ou mesmo as avaliações individuais (D3).

Cabe ressaltar a visão de um supervisor, que contrapõe os demais ao perceber no estágio uma atividade mais passiva, em que "Eles [estagiários] só acompanham e tiram dúvida em sala, não participam ativamente das aulas, ou seja, não é proposto aos mesmos a experiência de ministrar a aula com a escolha de um tópico (D5)".

Importante destacar que a maioria dos supervisores percebe no estágio docência a aprendizagem experiencial, à medida que instigam os discentes a buscarem a aprendizagem de maneira contínua por meio da transformação da experiência (Kolb, 1984). Para os discentes, mesmo aqueles que já tinham experiência com a docência, o estágio deu sentido às suas experiências prévias, tendo em vista o fato de poderem observar a atuação profissional de seus supervisores, como se percebe nos trechos a seguir:

[...] Pra mim, foi de extrema importância, porque eu consegui enxergar um lado da docência que eu não sabia nem que existia, né? Tanto na parte de utilização de metodologias diferentes, ativas, quanto no olhar do que de fato, de como o professor pode levar uma aula, no sentido de que eu tinha uma ideia muito, realmente assim, do que eu carregava, né? Muito estática. Faltava esse olhar mais amplo. [...]Foi um divisor de águas mesmo, consegui enxergar pontos que eu poderia, que eu já deveria ter melhorado e que eram coisas até meio que simples, óbvias, mas que eu sozinha não consegui despertar. O estágio docência me proporcionou essa oportunidade junto com, no caso, minha professora orientadora (E 19).

No começo, eu confesso que, quando me falaram que eu tinha que fazer dois semestres de estágio docência eu quis morrer. Eu falei: 'não é possível que eu tô dando aula há 5 anos e vou ter que fazer a disciplina de estágio docência'!. Mas eu confesso que valeu muito a pena. [...] Meu orientador também utiliza metodologias ativas, então eu também tive contato com coisas que não eram do meu hábito. Num segundo momento, no segundo estágio docência do doutorado, na parte de pesquisa, também eu achei muito interessante, porque, principalmente, do ponto de vista da orientação, aprendi muito com meu orientador, por exemplo, orientação de TCC foi uma lição pra mim. [...] Então, eu confesso que os estágios docência são importantes. E principalmente na nossa área, que não formam professores, que não é um curso de licenciatura, é bacharelado. Então eu acho que esse é um momento que para quem quer ser um professor, ter um norte (E 21).

A partir das falas dos entrevistados, constata-se a relevância do papel do estágio docência para essa formação. Por mais que os discentes tenham relatado certa resistência em realizar o estágio docência em virtude da experiência que já possuíam com o ensino, competências como utilizar uma metodologia diferente e organizar as atividades puderam ser desenvolvidas a partir da realização do referido componente curricular. Isso reflete a capacidade que o indivíduo tem de se conectar com experiências anteriores para promover novas aprendizagens (Merriam \& Bierema, 2013).

Outro ponto destacado nas entrevistas com os docentes diz respeito à função do estágio como um processo de reflexão sobre a prática e a relevância das reflexões dos estagiários durante o estágio docência, principalmente, no que se refere ao comportamento dos alunos no decorrer das aulas, como relata um dos entrevistados: 
Eles acabam refletindo e pensando... eles falaram, durante as observações mesmo, eles olham mais, às vezes, o comportamento dos alunos porque estão ali só pra isso mesmo, pra ficar observando como o professor está administrando a aula e como os alunos estão se comportando e eles ficam pensando: "Ah, e se eu fizesse assim, como que você acha.... Então eu acho que isso tem acontecido também, tem acontecido com os alunos, eles têm refletido sobre... "Ah, isso tem funcionado. Eu vejo que, quando você faz um exercício assim, os alunos se envolvem mais e tal". Eles têm tido essas reflexões sim (D3).

O papel do supervisor durante o estágio é crucial para que as reflexões se tornem significativas no processo de desenvolvimento profissional dos discentes, corroborando Joaquim et al. (2011), que destacam a importância da reflexividade na promoção do aprendizado e na geração do conhecimento em uma experiência significativa de aprendizagem. Observando a fala de uma docente é possível verificar a intencionalidade em proporcionar momentos de observação aos estagiários antes da atuação deles em sala de aula.

[...] deixo essa aula que eles vão ministrar mais pra frente, mais pro final do semestre, até pra que eles ganhem uma certa confiança, tenham mais segurança na hora de aplicar o conteúdo porque, às vezes, eles ficam meio inseguros mesmo, principalmente, no início (D3).

De acordo com os relatos dos discentes, a oportunidade que tiveram de acompanhar seus orientadores durante o estágio docência contribuiu para que eles analisassem suas posturas diante da sala, bem como o modo como eles se relacionavam com os alunos e a maneira como explicavam o conteúdo. É justamente nesse ambiente de observação, de imitação e de reprodução proporcionado pelo estágio docência que o aluno inicia sua construção enquanto docente (Santos \& Helal, 2015).

No entanto, o processo de observação da atuação do supervisor não foi suficiente para driblar a ansiedade e o nervosismo no momento em que os discentes tiveram que conduzir a aula, conforme descrito por eles.

[...] mas a insegurança, não de estar na frente, de falar em público, isso não é o problema. O problema era de se o que eu tava (sic) falando era certo. Então, esse é o maior ponto que me pegava, era se o que eu tava (sic) falando tinha sentido, tava (sic) certo, exemplificar, porque não é só falar a teoria, né? [...], mas conseguir exemplificar, contextualizar, cruzar com coisas que estão com dúvida, conseguir responder o que os alunos questionarem (E13).

E até chegar esse dia, eu ia prestando atenção no jeito que ela dava aula, no jeito que ela se portava, no jeito que ela fala com os alunos e, mesmo assim, a insegurança também existiu. Eu lembro que, no dia que fui dar a aula, eu tava (sic) muito inseguro, mas não era nem tanto por conta da matéria, porque eu acho que eu tinha até me preparado, porque, quando a gente sabe que vai ser confrontado, a gente se prepara até melhor[...] (E14).

Percebe-se que, ainda que houvesse insegurança por parte dos alunos, dada a responsabilidade de ter que ministrar uma aula na presença do professor supervisor, eles conectavam-se com aquilo que haviam observado anteriormente, ou seja, utilizavam a experiência do professor para norteá-los na condução da aula. Isso é compreensível, pois "o modo de aprender a profissão, conforme a perspectiva da imitação será a partir da observação, imitação, reprodução e, às vezes, reelaboração dos modelos existentes na prática consagrados como bons" (Pimenta \& Lima, 2004, p. 35). 
Ao serem questionados sobre uma possível conversa com os seus orientadores de estágio a respeito da insegurança, ou mesmo o nervosismo que os acompanhava nesse processo de aprendizagem em torno da prática docente, os alunos comentaram sobre o quanto o contato com o supervisor foi importante para eles, antes mesmo do início do estágio. Esse fato é corroborado pela fala de uma supervisora: "[...] é claro que existe ali um nervosismo, né? No início, mas, depois, eles falaram que acabaram relaxando e conseguiram também observar os alunos, como é que eles estavam se comportando [...]" (D3). Sobre esse aspecto, Rocha-de-Oliveira e Deluca (2017) defendem que a relação de proximidade que é estabelecida entre professor e aluno ao longo do estágio contribui para o aproveitamento do discente durante a atividade.

O momento posterior à aula ministrada pelos estagiários também é visto como parte importante do processo de reflexão, pois é nesse momento que supervisor e estagiário refletem sobre pontos positivos e negativos, além de trocarem experiências e percepções sobre a experiência obtida.

[...] Após a apresentação deles, [...] eu dou um feedback apresentando pontos fortes, pontos fracos, o que eu acho que precisava melhorar, né? E, em muitos casos, eu tenho orientandos que já são professores, eles já atuam como professores, mas, mesmo assim, eu não deixo de dar feedback, de dar sugestões, de mostrar aspectos que, talvez, pela experiência, eles não tenham aprendido (D4).

Com base no que foi apresentado, verifica-se o quanto o estágio docência pode contribuir para a formação do aluno de pós-graduação, tendo em vista a potencialidade de se associar o conhecimento teórico à prática do ensino, como sugerem Joaquim et al. (2013). Além disso, percebe-se a importância do feedback dos docentes no processo de formação dos pós-graduandos, quanto aos seus esforços de aprendizagem durante a realização do estágio, consoante ao que propõe Kolb e Kolb (2005). Nesse sentido, entende-se que a proximidade entre o professor supervisor e o discente no estágio docência é fundamental para o melhor aproveitamento dele nesta etapa de formação, à medida que o leva a refletir criticamente sobre o processo de ensino-aprendizagem (Rocha-de-Oliveira \& Deluca, 2017).

\subsection{Habilidades e competências proporcionadas pelo estágio docência}

Nessa categoria, foram analisadas as competências adquiridas no estágio docência pelos discentes, tomando-se por base as dez competências propostas por Zabalza (2003).

As competências que se destacaram na fala dos estagiários e dos supervisores divergiram em alguns pontos, mas convergiram ao destacar o planejamento do processo de ensino-aprendizagem e o processo de avaliação como competências adquiridas e desenvolvidas durante o estágio.

O planejamento do processo de ensino-aprendizagem talvez tenha sido uma das principais competências trabalhadas na realização do estágio docência, conforme o relato do grupo de discentes sem experiência com a docência, bem como o de alguns supervisores.

[...] eu acho que eles desenvolvem a capacidade de planejamento, de organização do tempo dentro de uma sala de aula, essa mesmo que eu já comentei, de distribuição do conteúdo no tempo da sala, e a capacidade também de tentar planejar as avaliações (D3).

$\mathrm{Eu}$ acho que o presente mais positivo que eu tirei do estágio docência foi lidar com o tempo. [...] tanto na parte de organizar a aula, de planejar, de pensar o que vai fazer, de pensar em como vai fazer, quanto na própria aula (E19). 
Planejar o processo de ensino-aprendizagem, enquanto competência contempla: as determinações legais, a estrutura curricular, na qual a disciplina está inserida, a experiência do docente em relação a ela, fatores que caracterizam os alunos (quantidade, qualificação anterior, interesses) e recursos disponíveis (Zabalza, 2003).

No entanto, a habilidade de planejar o processo de ensino-aprendizagem não é explorada por todos os orientadores de estágio, conforme a fala a seguir: "Não, disso [Planejamento do processo de ensinoaprendizagem] eles [alunos] não participam, não (D5)". Entende-se que isso representa uma falha no processo de formação para a docência, dada a importância da competência, principalmente, no ingresso na profissão.

Outra competência destacada, tanto pelos supervisores quanto pelos estagiários foi o desenvolvimento da habilidade de avaliar. Alguns alunos comentaram sobre as experiências que tiveram junto aos seus orientadores durante o estágio, principalmente, sobre a responsabilidade na elaboração de questões de provas e correção de atividades avaliativas.

A minha orientadora comentou a respeito da importância da prova e do cuidado que teria que ter pra fazer a prova, pra estar bem coerente com o que realmente tinha sido apresentado na sala de aula. Mas, assim, o que ela me falou é que, geralmente, o que ela usava é tentar trazer bem próximo do que realmente tinha sido trabalhado em sala [...] (E16).

Na época das avaliações, eu envolvo eles no sentido de que eles têm que me ajudar na elaboração de questões [...] Eles vão ter que estudar o conteúdo para elaborar questões. Então, eles vão, sim, propor questões pra essas avaliações e acredito que eles entendam, assim, a importância das avaliações né? (D2).

As falas descritas acima ilustram uma das proposições da teoria da Aprendizagem Experiencial, pois evidenciam o fato de a aprendizagem ser, na verdade, um processo de reaprendizagem. Assim, essa aprendizagem pode ser facilitada ao serem compartilhadas com os alunos ideias sobre um determinado tema (por exemplo) para que eles examinem, testem e acrescentem novas ideias, aprimorando-as efetivamente (Kolb \& Kolb, 2005).

Quanto à competência relacionada ao uso de tecnologias de ensino, houve divergência entre os discentes dos dois grupos focais. Alguns alunos afirmaram que seus professores eram mais tradicionais e não usavam tais ferramentas no processo de ensino, enquanto outros tiveram a oportunidade de aplicar tecnologias durante esse processo. Nesse sentido, uma aluna do grupo focal sem experiência com a docência relata: "Eu já não tive, porque a minha orientadora é mais tradicional. Giz, datashow, no máximo" (P11). Esse trecho corrobora a fala de uma supervisora que afirmou não utilizar técnicas de ensino diferentes e por isso, ela não teria o costume de incentivar seus estagiários a utilizá-las.

[...] eu, que não uso muitas tecnologias [de ensino], eu acho que um pouco por causa das disciplinas que eu lecionei nos últimos tempos, elas não dão muito espaço para eu tá aplicando esses novos, essas novas técnicas [...]. Ele não aprende, assim, muitas técnicas não, na minha disciplina [...] (D1).

Em contrapartida, trechos do grupo focal com alunos que já tinham experiência na docência retratam a utilização de técnicas de ensino diferentes das tradicionais, bem como ressaltam a importância do papel do supervisor ao incentivar e mostrar as diversas tecnologias existentes. Segundo Zabalza (2003), a capacidade de elaborar a metodologia e organizar as atividades consiste em escolher as estratégias de ensino, bem como formular atividades instrutivas e organizar os espaços voltados para a aprendizagem. Nesse sentido, com base nas falas dos participantes, nota-se que essa competência foi bastante explorada durante o estágio. 
No doutorado, por exemplo, eu tive a oportunidade de acompanhar a minha orientadora, né? E ela utiliza técnicas de aprendizagem diferentes, né? Então assim, eu pude acompanhar, participar, desenvolver coisas que eu não uso muito nas minhas aulas. (E17)

A questão da utilização de metodologias, porque realmente eu desconhecia. A gente sabe, a gente vê que existe algo do tipo, mas a gente não sabe que tem nome, tem forma de aplicar, que tem cenário ideal pra aplicar, então eu acho que isso me ajudou muito. E eu tive a mesma sensação, eu tive vontade "ah, eu quero voltar logo, que eu quero tentar isso aqui". (E19)

As falas dos discentes revelam que a partir das experiências vivenciadas no estágio docência, eles puderam conhecer melhor as estratégias de ensino, em virtude de seus orientadores/supervisores já as utilizarem. García e Conde (2003) afirmam que a teoria da Aprendizagem Experiencial pode ser associada à prática educativa ao se considerar que para cada estilo de aprendizagem podem ser aplicadas diferentes metodologias de ensino.

Diante dos relatos aqui apresentados, percebe-se que, no decorrer do estágio docência, os discentes tiveram a oportunidade de desenvolver algumas competências sugeridas por Zabalza (2003) e que são requeridas dos docentes, tais como: o planejamento do processo de ensino-aprendizagem, o manejo de tecnologias, a comunicação; a avaliação, a elaboração da metodologia e a organização das atividades. Essa conclusão corrobora o pensamento de Joaquim et al. (2013), à medida que pós-graduandos e docentes reconhecem o papel do estágio docência para o desenvolvimento de competências importantes para o exercício da docência, dado o contato inicial com o ambiente de ensino que esse componente curricular possibilita.

É importante destacar ainda que as competências apontadas pelos alunos e seus orientadores de estágio estão em conformidade com as habilidades propostas pela Resolução do PPGCC investigado nesta pesquisa. Dessa forma, entende-se que as competências propostas por Zabalza (2003) e identificadas neste estudo evidenciam que o objetivo do PPGCC ao oferecer o estágio docência é percebido pelos pós-graduandos. Tais achados trazem implicações relevantes, no que tange ao papel do programa para o processo de formação docente.

\subsection{Principais desafios enfrentados no decorrer do estágio docência}

A terceira categoria de análise refere-se aos principais desafios enfrentados no decorrer do estágio docência. Nela, seis subcategorias emergiram a partir da análise das transcrições das entrevistas e dos grupos focais. As subcategorias que mais se destacaram retratam os desafios em virtude da diversidade de métodos adotados pelos professores na condução do processo de estágio docência e para a (falta de) preparação do supervisor.

O primeiro destaque retratado, tanto na fala dos discentes quanto dos supervisores, refere-se às experiências heterogêneas que os alunos têm ao cursar o estágio docência. Conforme os participantes, o estágio é conduzido de forma diversa pelos supervisores, mesmo havendo uma resolução que norteia o processo.

A gente não tem a definição do que seria adequado ou o que se espera do estágio docência. Então, cada docente conduz de uma forma. [...] Mas eu acho que tinha que ter uma sistematização porque, se a gente tá pensando que existe o estágio docência pra formar professores no ensino da pós-graduação, eu vejo, assim, claramente, que alguns não são formados, pela maneira que é conduzido [...]. Ainda vira até piada: 'Nossa, mas você acompanha o professor na sala?! Não acredito que você faz isso', sabe? (E17). 
Bom, partindo da nossa experiência aqui no programa, eu acho que ainda existe uma heterogeneidade muito grande sobre a condução do estágio. Eu acho que não há uma padronização, né? [...] a gente precisa aprimorar ainda nesse sentido (D4).

Os comentários dos participantes acerca da forma como o estágio docência é conduzido corroboram o posicionamento de Bastos, Tourinho, Yamamoto \& Menandro (2011), pois evidenciam que os Programas de Pós-graduação parecem não saber como oferecer a formação pedagógica para os seus alunos. Isso porque o estágio supervisionado acaba apresentando formatos muito diferentes não só entre um programa e outro, mas dentro de um mesmo programa.

Dessa forma, mesmo havendo uma resolução acerca do estágio docência no programa pesquisado, a mesma não é capaz de garantir uniformidade quanto ao modo como ele ocorre. Talvez isso possa ser associado à falta de qualificação pedagógica dos professores responsáveis pela supervisão do estágio, o que compromete a formação de seus orientandos enquanto futuros docentes, uma vez que o estagiário espelha muitas de suas ações a partir da experiência que adquire durante o estágio.

A falta de qualificação pedagógica pode ser ainda associada à falta de preparação para ser supervisor. Conforme a fala de alguns supervisores do estágio, um dos desafios enfrentados diz respeito à falta de preparação para conduzir esse processo.

Bom, eu acho que o primeiro ponto é que a gente não foi preparado pra isso, né? A gente não foi... a gente não recebeu instruções sobre como orientar o estagiário. Então, por exemplo, nos primeiros, era mais difícil. Aí, depois, a gente vai aprendendo com a experiência, com as pesquisas que a gente faz, mas eu percebo que tem muitos colegas que, às vezes, tem mais dificuldade do que a gente pra conduzir esse tipo de orientação (D4).

As falas dos docentes podem ser compreendidas a partir da perspectiva de Bastos et al. (2011), pois, segundo os autores, a formação pedagógica não é exigida do professor universitário, porque considerase suficiente o domínio de conhecimentos específicos. Esse fato acaba repercutindo na pós-graduação, à medida que os mestres e doutores formados por esses cursos podem assumir a docência sem que tenham as competências pedagógicas necessárias para atuarem no ensino superior (Bastos et al., 2011). Dessa forma, deve-se reconhecer que a prática do ensino requer saberes e habilidades que podem ser adquiridos ou desenvolvidos a partir de um processo de formação pedagógica capaz de preencher a lacuna deixada pela formação inicial ou pela formação proporcionada pelos programas de pós-graduação (Junges \& Behrens, 2015).

É importante considerar que a formação docente não se limita simplesmente ao fato de o pósgraduando ter contato com a sala de aula ao substituir o seu professor orientador, assim como essa formação não pode ser garantida com o oferecimento de uma ou mais disciplinas voltadas para a formação pedagógica (Bastos et al., 2011). Conforme os autores, esse tipo de formação requer mais dos Programas de Pós-Graduação, porém, talvez eles não saibam como oferecê-la.

Em síntese, os desafios enfrentados e aludidos, tanto por supervisores, quanto por estagiários, dizem respeito às experiências heterogêneas em torno do estágio, bem como aos desafios de se conduzir esse processo de formação dos futuros docentes, de modo a permitir a aquisição de habilidades e competências em tão pouco tempo. Esse processo se torna ainda mais difícil ao considerar que muitos dos supervisores de estágio não receberam preparação para a docência e, ainda assim, são responsáveis por conduzir a aprendizagem de seus alunos com base nos erros e acertos que tiveram em suas experiências anteriores.

Diante desses desafios, cabe a reflexão e o questionamento: Quais medidas poderiam ser adotadas pelos PPGCCs, a fim de garantir não só a sistematização do estágio, mas, principalmente, o aproveitamento do discente em relação a esse componente curricular? 


\subsection{Síntese dos Resultados}

A partir da análise dos grupos focais com os pós-graduandos (sem experiência com a docência e com experiência na docência ao realizar o estágio docência) e das entrevistas realizadas com os docentes acerca do estágio docência, observa-se que as percepções, embora distintas, são muito positivas em relação a esse componente curricular. Nesse sentido, a Tabela 4 sintetiza os principais aspectos observados nesses grupos.

Tabela 4

Estágio Docência na Formação Docente

\begin{tabular}{|c|c|c|c|}
\hline Categorias & $\begin{array}{l}\text { Grupo sem experiência } \\
\text { com a docência }\end{array}$ & $\begin{array}{l}\text { Grupo com experiência na } \\
\text { docência }\end{array}$ & Docentes \\
\hline $\begin{array}{l}\text { Função do estágio } \\
\text { docência }\end{array}$ & $\begin{array}{l}\text { - Aproximação com a } \\
\text { atividade docente } \\
\text { - Oportunidade de } \\
\text { vivenciar os desafios que } \\
\text { envolvem a docência } \\
\text { - Contribuição para a } \\
\text { formação didático- } \\
\text { pedagógica }\end{array}$ & $\begin{array}{l}\text { - Reflexão e } \\
\text { aprimoramento em torno } \\
\text { das próprias práticas } \\
\text { docentes } \\
\text { - Aprendizagem como um } \\
\text { constante processo }\end{array}$ & $\begin{array}{l}\text { - Oportunidade do aluno vivenciar } \\
\text { a prática da sala de aula } \\
\text { - Aproximação do aluno } \\
\text { com o processo de ensino: } \\
\text { planejamento da aula, } \\
\text { elaboração das atividades e das } \\
\text { avaliações } \\
\text { - Reflexão sobre a prática docente }\end{array}$ \\
\hline $\begin{array}{l}\text { Habilidades e } \\
\text { competências } \\
\text { proporcionadas } \\
\text { pelo estágio } \\
\text { docência }\end{array}$ & $\begin{array}{l}\text { - Conhecimentos ligados } \\
\text { à docência e os seus } \\
\text { desafios } \\
\text { - Planejar o processo de } \\
\text { ensino-aprendizagem } \\
\text { - Avaliar }\end{array}$ & $\begin{array}{l}\text { - Manejo de tecnologias } \\
\text { - Elaborar a metodologia e } \\
\text { organizar as atividades; } \\
\text { Tutoria }\end{array}$ & $\begin{array}{l}\text { - Planejar o processo de ensino- } \\
\text { aprendizagem } \\
\text { - Avaliar } \\
\text { - Capacidade de comunicar-se e } \\
\text { relacionar-se com os alunos }\end{array}$ \\
\hline $\begin{array}{l}\text { Desafios } \\
\text { enfrentados ao } \\
\text { longo do processo } \\
\text { de estágio }\end{array}$ & $\begin{array}{l}\text { - Experiências } \\
\text { heterogêneas dos } \\
\text { discentes } \\
\text { - Formatos distintos de } \\
\text { estágio }\end{array}$ & $\begin{array}{l}\text { - Experiências } \\
\text { heterogêneas dos } \\
\text { discentes } \\
\text { - Formatos distintos de } \\
\text { estágio }\end{array}$ & $\begin{array}{l}\text { - Experiências heterogêneas dos } \\
\text { discentes } \\
\text { - Formatos distintos de estágio } \\
\text { - Falta de qualificação pedagógica } \\
\text { do docente responsável pela } \\
\text { supervisão de estágio } \\
\text { - Curta duração }\end{array}$ \\
\hline
\end{tabular}

Fonte: elaborado pelas autoras.

A partir da Tabela 4, é possível perceber as principais contribuições, bem como os desafios que envolvem o estágio docência. Com base nas percepções dos grupos apresentadas anteriormente, verificase a importância do estágio docência para a formação docente, seja ela inicial ou continuada. Afinal, devese reconhecer que o aprendizado ocorre em maior grau quando as pessoas têm a oportunidade de agir, fazendo descobertas que beneficiem a si mesmas (Behr \&Temmen, 2012).

Nesse sentido, entende-se que é possível associar o estágio docência à teoria da Aprendizagem Experiencial, tendo em vista que a apropriação das experiências vividas pelos indivíduos, a partir de uma ação e reflexão contínua pode ser aperfeiçoada no ambiente do estágio (Kolb, 1984). Verificouse que o estágio docência proporciona tais experiências relacionadas à formação pedagógica dos pósgraduandos, principalmente por proporcionar a eles uma série de vivências que os motiva a atuarem em favor do próprio aprendizado (Behr \& Temmen, 2012). Dessa forma, a experimentação por meio do estágio docência permite o desenvolvimento de competências necessárias no processo de ensino, aliando teoria à prática (Joaquim, Nascimento, Vilas Boas \& Silva, 2011; Joaquim \& Vilas Boas, 2011; Santos \& Helal,2015). 


\section{Considerações Finais}

O presente estudo teve como objetivo identificar as competências desenvolvidas no estágio docência para a qualificação docente, a partir da percepção dos pós-graduandos stricto sensu da área contábil e dos docentes supervisores do estágio.

Os resultados da pesquisa evidenciaram a responsabilidade dos docentes orientadores do estágio docência, no que se refere ao acompanhamento das atividades realizadas nessa modalidade de ensino. Os achados indicam também que as experiências vivenciadas pelos alunos no estágio são espelhadas nos docentes. Além disso, pode-se verificar a contribuição do estágio docência para o desenvolvimento de competências necessárias à docência, como as sugeridas por Zabalza (2003): habilidade para o planejamento do processo de ensino-aprendizagem; melhorias na comunicação, no relacionamento com os alunos, nas formas de avaliar, dentre outras.

Nesse sentido, o estágio serviu não apenas como momento de aprimoramento, mas de reflexão em torno das próprias práticas de aprendizado e, principalmente, de estímulo para o desenvolvimento das competências requeridas na docência. Os estagiários puderem vivenciar, de fato, o processo de ensino-aprendizagem, à medida que tiveram a chance de associar o conhecimento teórico à prática da sala de aula (Joaquim et al., 2013).

De maneira geral, os resultados do estudo revelaram a necessidade de se desenvolver artifícios que assegurem a sistematização do estágio docência, a fim de garantir que as experiências vivenciadas nessa atividade contribuam de maneira efetiva para a formação docente do aluno.

Foram identificadas importantes implicações e contribuições com os achados deste estudo. É notável que a preocupação em torno do estágio docência deve se concentrar na forma como ele está sendo conduzido pelos programas de pós-graduação stricto sensu. Nesse sentido, os objetivos educacionais em torno do estágio devem ser muito claros, assim como as diretrizes que norteiam sua realização. Além disso, deve haver algum mecanismo que assegure que o discente terá um acompanhamento adequado por parte do professor que o orienta/supervisiona, de modo que esse professor deve possuir uma formação didáticopedagógica que o permita assumir tal responsabilidade, da mesma forma que ele deve ter clareza das suas responsabilidades enquanto supervisor de estágio.

Entre as limitações desta pesquisa, destaca-se o fato dos grupos focais, bem como as entrevistas terem sido realizadas em um único PPGCC. Entende-se que expandir a coleta de dados por meio da colaboração de outros programas de pós-graduação da área contábil poderia trazer maiores contribuições e reflexões acerca da temática investigada por esta pesquisa.

Para futuros trabalhos, sugere-se que seja investigada a forma como os PPGCCs têm acompanhado o estágio docência e quais ações têm sido desenvolvidas para garantir o aproveitamento do aluno ao cursar esse componente curricular.

\section{Referências}

Alves, A. V. S.; Barbosa, C. R. \& Dib, A. (2016). Fundamentos pedagógicos e a formação do docente: a experiência do estágio à docência. Revista Docência do Ensino Superior, 6(2), PP. 63-88. DOI: https:// doi.org/10.35699/2237-5864.2016.2186

Andere, M. A. \& Araujo, A. M. P. de. (2008). Aspectos da formação do professor de ensino superior de ciências contábeis: uma análise dos programas de Pós-graduação. Revista Contabilidade \& Finanças, 19(48), PP. 91-102. DOI: https://doi.org/10.1590/S1519-70772008000300008

Antonelli, R. A.; Colauto, R. D. \& Cunha, J. V.A. (2012). Expectativa e satisfação dos alunos de ciências contábeis com relação às competências docentes. Revista Iberoamericana sobre Calidad, Eficacia y Cambio em Educación, 10(1), 74-91. Recuperado de https://www.redalyc. org/pdf/551/55123361006.pdf. 
Bastos, A. V. B.; Tourinho, E. Z.; Yamamoto, O. H. \& Menandro, P. R. (2011). Réplica 1- Formar docentes: em que medida a pós-graduação cumpre esta missão? Revista de Administração Contemporânea, 15(6), pp. 1152-1160. Recuperado de https://www.redalyc.org/pdf/840/84020810010.pdf.

Behr, T. \& Temmen, K. (2012). Teaching experience - improving teacher education with experiential learning. International Journal on New Trends in Education and Their Implications, 3 (3), pp. 60-73. Recuperado de http://www.ijonte.org/FileUpload/ks63207/File/06.behr.pdf.

Capes. (2014). Mestrado e doutorado: o que são? Ministério da Educação. Recuperado de http://capes. gov.br/avaliacao/sobre-a-avaliacao/mestrado-e-doutorado-o-que-sao.

Cavalcante, R. B.; Calixto, P.; Pinheiro, M. M. K. (2014). Análise de conteúdo: considerações gerais, relações com a pergunta de pesquisa, possibilidades e limitações do método. Inf. \& Soc.: Est., 24(1), pp.13-18. Recuperdo http://basessibi.c3sl.ufpr.br/brapci/_repositorio/2015/12/pdf_ba8d5805e9_0000018457.pdf.

Comunelo, A. L.; Espejo, M. M. S. B.; Voese, S. B. \& Lima, E. M. (2012). Programas de pós-graduação em contabilidade: sua contribuição na formação de professores e pesquisadores. Enfoque: Reflexão Contábil, 31(1), pp. 7-26. Recuperado de http://periodicos.uem.br/ojs/index.php/Enfoque/article/ view/13375/0

Ferreira, M. M. \& Hillen, C. (2015). Contribuições da pós-graduação stricto sensu para o aprendizado da docência de professores de Contabilidade. Enfoque, 34(3), 125-143. Doi: https://doi.org/10.4025/ enfoque.v34i3.29031

Gil, A. C. (2008). Didática do ensino superior. São Paulo: Atlas.

Hillen, C.; Laffin, M. \& Ensslin, S. R. (2018). Proposições sobre formação de professores na área Contábil. Arquivos Analíticos de Políticas Educativas, 26(106), pp. 1-30. Doi: DOI: 10.14507/epaa.26.

Joaquim, N. F. \& Vilas Boas, A. A. V. (2011). Tréplica: formação docente ou científica - o que está em destaque nos programas de pós-graduação? Revista de Administração Contemporânea, 15(6), pp. 1168-1173. Recuperado de http://www.spell.org.br/documentos/ver/1753/.

Joaquim, N. de F.; Vilas Boas, A. A. \& Carrieri, A. de P. (2013). Estágio docente: formação profissional, preparação para o ensino ou docência em caráter precário? Educação e Pesquisa, 39 (2), pp. 351 365. Recuperado de http://www.redalyc.org/articulo.oa?id=29826312005.

Joaquim, N. F.; Nascimento, J. P. B.; Vilas Boas, A. A. \& Silva, F. T. (2011). Estágio docência: um estudo no Programa de Pós-Graduação em Administração da Universidade Federal de Lavras. Revista de Administração Contemporânea, 15(6), 1137-1151. Recuperado de https://www.redalyc.org/ pdf/840/84020810009.pdf.

Junges, K. dos S. \& Behrens, M. A. (2015). Prática docente no ensino superior: a formação pedagógica como mobilizadora de mudança. Perspectiva, 33 (1), 285-317. Recuperado de https://periodicos. ufsc.br/index.php/perspectiva/article/viewFile/2175795X.2014v33n1p285/31220.

King, N. (2004). Using interviews in qualitative research. In: Cassel, C. \& Symon, G. Essential guide to qualitative methods in organizational research. Londres: SAGE Publications, p. 11-22. DOI: http:// dx.doi.org/10.4135/9781446280119.n2

Kolb, D. A. (1984) Experiential learning: experience as the source of learning and development. Englewoods Cliffs: Prentice Hall. Recuperado de https://s3.amazonaws.com/academia.edu.documents/34850950/ Kolb.pdf?response-content-disposition

Kolb, A. Y. \& Kolb, D. A. (2005). Learning styles and learning spaces: enhancing experiential learning in higher education. Academy of Management Learning \& Education, 4 (2), pp. 193-212. Recuperado https://www.jstor.org/stable/40214287?seq=3\#page_scan_tab_contents. 
Laffin, M. \& Gomes, S. M. S. (2014). The Pedagogical Training of Teachers in Stricto Sensu Programs in Accounting Sciences. Australian Journal of Basic and Applied Sciences, 8(18), pp. 255265. Recuperado de http://www.repositorio.ufba.br:8080/ri/bitstream/ri/27936/1/The $\% 20$ Pedagogical\%20Training\%20of\%20Teachers\%20in\%20stricto\%20sensu\%20Programs\%20in\%20 Accounting\%20Sciences.pdf.

Lapini, V. (2012). Panorama da formação do professor em Ciências Contábeis pelos cursos stricto sensu no Brasil. 2012. 76f. Dissertação (Mestrado em Ciências), Universidade de São Paulo, Ribeirão Preto.Recuperado de https://www.teses.usp.br/teses/disponiveis/96/96133/tde-04052012-135541/ publico/VivianCLapini_Original.pdf

Liston, D. P., \& Zeichner, K. M. (1990). Reflective teaching and action research in preservice teacher education. Journal of Education for Teaching, 16(3), 235-254. DÓI: https://doi. org/10.1080/0260747900160304

Masetto, M. T. (2012). Competência pedagógica do professor universitário. 2. Ed. São Paulo: Summus. Recuperado de https://docplayer.com.br/5483449-Marcos-tarciso-masetto-competenciapedagogica-do-professor-universitario.html

Merriam, S. B. (2009). Qualitative research: a guide to design and interpretation. San Francisco: Jossey-Bass.

Merriam, S. B. \& Bierema, L. L. (2013). Adult learning: linking theory and practice. San Francisco: JosseyBass.

Miranda, G. J. (2010). Docência universitária: uma análise das disciplinas na área da formação pedagógica oferecidas pelos programas de pós-graduação stricto sensu em Ciências Contábeis. Revista Educação e Pesquisa em Contabilidade, 4(2), pp. 81-98. Recuperado de http://www.repec.org.br/index.php/ repec/article/view/202.

Nganga, C. S. N.; Botinha, R. A.; Miranda, G. J. \& Leal, E. A. (2016). Mestres e doutores em

Contabilidade no Brasil: análise dos componentes pedagógicos de sua formação inicial. Revista Iberoamericana sobre Calidad, Eficacia y Cambio en Educación, 14(1), pp. 83-99. Doi: 10.15366/ reice2016.14.1.005

Nogueira, D. R.; Fadel, M. O. \& Takamatsu, R. T. (2012) Em busca da essência de um bom professor: uma análise sobre a percepção discente dos cursos de Pós-graduação na área de negócios. ReCont: Registro Contábil, 3(3), pp. 12-31. Recuperado de http://www.seer.ufal.br/index.php/registrocontabil/article/ view/604/420.

Patrus, R. \& Lima, M. C. (2014). A formação de professores e de pesquisadores em administração: contradições e alternativas. Revista Economia \& Gestão, 14 (34), pp. 4-29. Recuperado de http://www.spell.org. $\mathrm{br} /$ documentos/ver/28772/a-formacao-de-professores-e-de-pesquisadores-em-administracao-contradicoes-e-alter-tivas

Pimenta, S. G. (2009). A profissão professor universitário: processos de construção da identidade docente. In: Cunha, M. I.; Soares, S. R.; Ribeiro, M. L. Docência universitária: profissionalização e práticas educativas. Feira de Santana: UEFS Editora.

Pimenta, S. G. \& Lima, M. S. L. (2004). Estágio e docência. São Paulo: Cortez.

Puentes, R. V.; Aquino, O. F. \& Neto, A. Q. (2009). Profissionalização dos professores: conhecimentos, saberes e competências necessários à docência. Educar, vol.(34), pp. 169-184. Recuperado de http:// www.scielo.br/pdf/er/n34/10.pdf http://www.scielo.br/pdf/er/n34/10.pdf

Rezende, M. G. \& Leal, E. A. (2013). Competências requeridas dos docentes do curso de Ciências Contábeis na percepção dos estudantes. Sociedade, Contabilidade e Gestão, 8(2), pp. 145-160. Recuperado de https://revistas.ufrj.br/index.php/scg/article/view/13295. 
Rocha-de-Oliveira, S. \& Deluca, G. (2017). Aprender e ensinar: o dueto do estágio docente. Cadernos EBAPE.BR, 15(4), 974-989. Disponível em: <http://www.scielo.br/pdf/cebape/v15n4/1679-3951cebape-15-04-974.pdf>.

Santana, A. L. A.; Araújo, A. M. P. (2011). Aspectos do perfil do professor de Ciências Contábeis e seu reflexo no Exame Nacional de Desempenho dos Estudantes (ENADE) - um estudo nas universidades federais do Brasil. Contabilidade Vista \& Revista, 22(4), pp. 73-112. Recuperado de http://www. spell.org.br/documentos/ver/9944

Santos, K. C. G. dos \& Helal, D. H. (2015). O estágio docente e o desenvolvimento de competências: um estudo no Programa de Pós-Graduação em Administração da Universidade Federal da Paraíba. Revista Gestão \& Conhecimento, 9(1), pp.1-20. Recuperado de https://www.facet.br/gc/artigos/ resumo.php?artigo $=90$.

Tolentino, J. E. F.; Silva, R. M. P.; Costa, A. J. B. \& Neto, L. M. A. (2014). O perfil esperado de um professor de contabilidade: uma análise a partir dos estudantes da cidade de Barcelos - Portugal. Revista Catarinense da Ciência Contábil, 13(39), 09-20. DOI: DOI: 10.16930/2237-7662/rccc.v13n39p9-20

Wall, M. L.; Prado, M. L. \& Carraro, T. E. (2008). A experiência de realizar um estágio docência aplicando metodologias ativas. Acta Paulista de Enfermagem, 21(3), pp. 515-519. Recuperado https://www2. unifesp.br/acta/pdf/v21/n3/v21n3a22.pdf.

Zabalza, M. A. (2003). Competencias docentes del profesorado universitario: calidad y desarrollo profesional. Madrid: Narceas Ediciones. 